\title{
L'admiration, études recueillies par Delphine Denis et Francis Marcoin
}

\section{Fatima Pilone}

\section{Q OpenEdition \\ 1 Journals}

\section{Edizione digitale}

URL: http://journals.openedition.org/studifrancesi/37012

DOI: 10.4000/studifrancesi.37012

ISSN: 2421-5856

\section{Editore}

Rosenberg \& Sellier

\section{Edizione cartacea}

Data di pubblicazione: 1 juillet 2005

Paginazione: 222

ISSN: 0039-2944

\section{Notizia bibliografica digitale}

Fatima Pilone, «L'admiration, études recueillies par Delphine Denis et Francis Marcoin», Studi Francesi

[Online], 145 (XLIX | I) | 2005, online dal 30 novembre 2015, consultato il 18 avril 2021. URL: http:// journals.openedition.org/studifrancesi/37012 ; DOI: https://doi.org/10.4000/studifrancesi.37012

Questo documento è stato generato automaticamente il 18 avril 2021.

\section{(c) $(1) \odot \odot$}

Studi Francesi è distribuita con Licenza Creative Commons Attribuzione - Non commerciale - Non opere derivate 4.0 Internazionale. 


\title{
L'admiration, études recueillies par Delphine Denis et Francis Marcoin
}

\author{
Fatima Pilone
}

\section{NOTIZIA}

AV. VV., L'admiration, études recueillies par Delphine DENIS et Francis MARCoIN, Artois Presses Université, Centre de Recherches Littéraires « Imaginaire et Didactique «, Arras, 2003, pp. 213.

1 Delphine DENIS apre questa raccolta di studi menzionando Stendhal, considerato lo scrittore per eccellenza in relazione al sublime, al concetto di ammirazione come estasi, a quella sensazione di fascino che alcuni psicanalisti hanno definito appunto la "Sindrome di Stendhal" e che ben ci aiuta a comprendere cosa avviene nel moment admiratif.

2 Tutte e quattro le sezioni dell'opera comprendono testi di molti studiosi, che affrontano il tema dell'ammirazione secondo punti di vista anche molto diversi tra loro, da quello sociologico a quello filosofico, da quello storico a quello più prettamente letterario.

3 La prima parte, intitolata Politique de l'admiration, comprende i seguenti saggi: Admirer, critiquer di Francis MARCOIN; Le paradoxe de l'admiration di Charles COUTEL, che analizza il "movimento dello sguardo " secondo un taglio filosofico, giungendo alla conclusione che lo statuto dell'ammirazione cambia a seconda dei presupposti metafisici ed epistemologici dell'autore; Trois courts exercices plus un. Vers la poétique de l'admiration di Serge MARTIN, che offre alcuni esercizi per la ricerca, in ambito poetico, della sublime sensazione di infinito; Le canon, les classiques et l'admiration di William MARX, che fornisce una breve storia del canone e la teoria del modello di Harold Bloom; L'admiration dans l'enseignement littéraire depuis la fin du XIXe siècle di Violaine HOUDART-MEROT, che rivela la funzione centrale, nell'insegnamento secondario dal XIX secolo agli anni '60 in Francia, dell'ammirazione, della formazione del gusto e della formazione morale. 
4 La seconda parte porta il titolo De quelques passeur e propone i seguenti saggi: L'admiration ou la "vie vraie " de Valéry Larbaud di Catherine Douzou; Lecture, critique et admiration à travers les exemples de Gide et Gracq di Emmanuel FRAISSE; Inconvenance de Jaques Rivière, l"admiration comme acte critique di Jérôme ROGER, secondo il quale il vero lavoro del critico è quello di mettere il lettore nella condizione di rimanere attento, attraverso proprio il concetto di ammirazione.

5 La terza parte, De quelques modalités, si apre con lo studio di Jean LECOINTE, Modalités de l'admiration: la critique exclamative au XVI siècle en France; continua con quello di Sophie HACHE, Le saisissement de l'âme : sublime et admiration à l'age classique ; con La bibliothèque de la Pléiade comme bibliothèque de l'admiration. A propos d'une citation d'André Malraux di Nicolas RENOULT e, per finire, con L'admiration, une passion critique di Christine NOILLECLAUZADE.

6 La quarta ed ultima parte, De quelques objets, si apre con il saggio di Alain BUISINE, Venise l'admirable, che sottolinea il fascino che la città di Venezia esercita dal XIII secolo, e in cui il corpo urbano è visto come une fête du paraître. Lo studio di Charles GRIVEL, Adorer détester (en littérature populaire, et comment) evidenzia come alcuni oggetti siano fortemente legati ai sentimenti che possono provocare (ammirazione, adorazione, odio, disgusto); la materia "popolare" è il romanesque, che chiama in causa il lettore come vero e proprio attore del libro, in una memoria "a ripetizione". Anne CHAMAYOU, con lo studio Rousseau devant ses lecteurs: Julie, Narcisse et Pygmalion, porta l'attenzione su una frase dello scrittore Je m'adore dans ce que je fais, in un processo di interiorizzazione di un ideale di sé, presentato dalle figure della finzione. A chiudere questa sezione, e con esso l'intera raccolta, Bernard DESPORTES, in Truinas, parla del luogo "ammirevole" dove visse André du Bouchet fino alla morte nel 2001. 